\title{
EDITORIAL
}

\section{Management studies in context: International, interconnected, yet still unique}

As Peter Galvin noted in the editorial relaunch of $J M O$, 'globalisation does not necessarily equate with homogeneity' 'the world remains close to as heterogeneous as ever, and that it is the level of interconnectedness that is increasing' (2014: 1). It is this notion of interconnectedness which unites the seven papers presented in this edition of $J M O$. While each paper resides within traditional areas of human resource management, from organisational justice through to job satisfaction, they do so in a way in which each challenges assumptions of one 'best way' or of simple answers. Each is clearly presented as context-driven research to represent a move away from the pervasive academic paradigm of 'gap spotting' as the benchmark for publishable research.

The need for research, which is not only important but also interesting, is a common theme in discussing publishable research. However, there is a third area - relevance - that does not receive the same level of attention. The notion of relevance requires our research to speak to and engage a wider community. Within the academic sphere, relevance is intertwined with the vexed issue of impact, but we suggest that this is not just in terms of what Pettigrew aptly describes as 'the retreat to defining scholarship just in terms of publication in A-rated journals' (2011: 348). Instead, impact is the more nuanced view (which Pettigrew notes was a feature of a European Social Research Council report way back in 1994!), which found that 'One of our themes is that management research still does not make enough impact on users and thus on management practice. But its capacity to do so is not in doubt' (cited in 2011: 349). While focussed on the notion of theoretical contributions, writing in the Academy of Management Review some 17 years after the ERSC report, Corley and Gioia express similar frustration. They offer that;

If we do not change our scholarly traditions in ways that enhance theoretical relevance to practice and sensegiving potential to the wider audiences, then we will continue to underperform our adaptive role in society and condemn ourselves to increasing irrelevance and diminishing influence in describing, explaining, understanding, and improving organizations and their management (Corley \& Gioia, 2011: 29).

With the new focus of JMO as well as these two cautions to the fore, we would like to briefly introduce the seven papers that are the basis of this issue and show how each contributes to research that covers a range of countries, is context specific and is relevant.

The first paper, 'Sacred activism through seva and khidmat: Contextualising management and organisations in South Asia' is an invited contribution that epitomises this blend of contextualisation and internationalisation. Focussed on South Asia, the paper is written as a thought provoking one that directly questions the interwoven and complex nature of this vast and populous region to examine the challenges to conventional Western wisdom. It is a wisdom that the authors suggest 'which often stereotype and rubricise consciousness putting people and organisations into boxes which become impenetrable'. The different realities and opportunities presented by religion, culture, ethnicity, gender and governance and the role they then play in the management of organisations in South Asia is deftly outlined. The importance of contextualising management practice within the wider world of the history and the religious traditions of a region are explored in depth through an examination of the polarising and pluralistic practices of seva and khidmat. These notions are explained in a way that 
resonates with a Western mindset where hopes for a greater good are also seen as a way to address perceptions of the growing inequity and greed persist in the management of many organisations.

The authors provide examples and draw on heavily on some of the acknowledged thought leaders in the area but their own explanation of 'the focus of the Western model of management is on knowledge worker, the South Asian approach may be seen as focused on the notion of wisdom worker' provides a succinct view of the importance of this paper. The very real tensions, as well as the value of developing a deeper understanding in ways which can enrich all parties, is offered as a very real possibility.

The challenges of management in the 21 st century is also a theme of the second paper. Titled 'Organizational justice of work-life balance', this paper compares perceptions of organisational justice between two groups; professionals/managers and non-professional employees across Australia. The authors place this research within the context of the increasing inequality of power within contemporary organisations and societies (Ozbilgin et al., 2011). They also note that work-life balance (WLB) within Australia is an area where employees are increasingly dissatisfied (Pocock, 2005, 2008; Campbell, 2007; ABC News, 2010). In line with the challenging nature of the issue, the paper adopts the perspectives of organisational level stratification and workers' power status (Lambert \& Haley-Lock, 2004; DiTomaso, Post, \& Parks-Yancy, 2007; Lambert, 2009) with a critical social science perspectives (Ozbilgin et al., 2011) as its theoretical framework. It is a structure that provides for a view of WLB that allows the paper to not only be critical of the blind spot in WLB research but to also identify the need for data that captures the changing nature of demographic workforce compositions in ways which reveal the differences within employees' work-life experiences within social and historical contexts. It is a view further enhanced by the operationalisation of organisational justice as taxonomy of procedural, distributional and interactional justice from which to examine the perceptions of employees about WLB-related work incidents.

The authors add to the value of their research by adopting a mixed methods approach and this sees the two groups' justice perceptions first examined quantitatively tested and then, followed up with qualitatively interviews. The quotes used in the paper from the interviews add a great deal of power (and relevance), to the findings that not only are there differences in the levels but also in the nature of the justice each group perceived. The higher positive perceptions of the managerial/ professional group over the non-professional groups speak directly to the need for managers through to policy makers and authorities who formulate and implement WLB initiatives. As authors suggest, these findings raise important implications in a world where workloads not only working hours are rising as well as social stratification.

The third paper, 'What matters in the relationship between mentoring and job-related stress?' moves to what looks like a better established area - only to reveal that the literature on the relationship between mentoring and job-related stress has yielded mixed and inconclusive results. The domination of the research in this area by western perspectives is another challenge the authors set themselves. Drawing on Tsui (2004), they question transportability of social science models from one society to another. They offer the research context of China, as a nation undergoing profound transitions in institutional rules, social norms and values (Farh, Hackett, \& Liang, 2007) and where the workforce values are increasingly diverse, ranging from traditionalist Chinese to those with a strong international cultural influence (Ralston, Egri, Steward, Terpstra, \& Kaicheng, 1999). This context provides for an examination of the potential conflict between protégés individual traditionality and their trust in their mentor as moderators on the relationship between mentoring and job-related stress.

While the research findings confirm that mentoring can reduce or even prevent protégé stress, a more relevant insight the authors provide is that they are able to offer a possible explanation for the history of mixed results within prior studies in the past by adding a contingency perspective to their investigation. The need for attention to be paid to the role of individual characteristics is highlighted 
and moves the paper away from the homogenising view of mentoring as always a good thing (a point the authors make quite strongly).

Our fourth paper, 'The individual and congruence effects of core self-evaluation on supervisor-subordinate guanxi and job satisfaction' retains an Asian focus but moves to Taiwan. It also reverses the focus on research concepts as West to East process to look at how core self-evaluations and job satisfaction relate to guanxi (defined here as the quality of social interaction outside of work). While the paper provides begins with a standard identification of the research gap (here, the lack of research on guanxi as a workplace issue), the incorporation of core self-evaluations as an antecedent to supervisor-subordinate guanxi provides adds a unique perspective. Grounding this within the outcome of job satisfaction should return both academic and practitioner readers to well-known territory.

From the literature review to the discussion, it is this interplay between detail about the context (with explanation as to the operationality of the concept of guanxi), with well-known concepts, such as core self-evaluations, social exchange and leader-member exchange theory that highlight the way such research expands both the boundaries of our understanding as well as accepted practice. The results of the study thus find both confirmation of earlier work - for instance, Liden and Graen (1980) findings that those who report high-quality relationships with their supervisors are more satisfied, as well as new insights into the role hierarchy may play in core self-evaluations and jobrelated outcomes. As the authors suggest, they add an 'important nuance to the acclaimed benefits of guanxi in the workplace.

The fifth paper, 'A Maori approach to management' while moving the country of focus to New Zealand, maintains the reversal of management perspective, which characterised the last paper. It is an explicit theme of this paper as the authors suggest that, while recent research has sought to contextualise management theory to the local environment (Geare, Cambell-Hunt, Ruwhiu, \& Bull, 2005; Aotahi Ltd, 2008; Jones, 2011). Western management theory fails to adequately explain the experience of the Maori people of New Zealand. It is a provocative suggestion and one which allows a number of questions to be asked, from the perspectives that can be offered by researchers who have indigeneity as their dominant paradigm, through to questioning the relevance and impact having an indigenous perspective has for management theory and organisational performance of organisations.

The authors also anchor their research within an historical context (within post-colonial discourse Smith, 1999; Jack \& Westwood, 2009), to offer a synthesis of traditional and contemporary Maori management in a globalised world economy. It is a perspective which offers new insight when they then apply Fayol's four functions of management (planning, leading, organising and controlling). The result of reading ideas many are so familiar with but with this different perspective is where this issue of context that we began this editorial with, emerges vividly. The tendency for management, as a discipline, to be homogenising disappears and the reality of the heterogeneity of day-to-day organisational life, as a lived experience is an important contribution of this paper.

The sixth paper, 'Key considerations for facilitating employment of female Sudanese refugees in Australia' moves back to the Australian context, while introducing a cultural heterogeneity perspective and investigating employment opportunities for female Sudanese refugees. The authors use an interpretative and multi-source approach to analyse information from academic literature, Australian government programs and data gathered through in-depth interviews. From the brief overview on the Australia's Humanitarian Program through to the turbulent history and ethnic complexity of Sudanese people, the first individual-in-context contribution of the paper is to provide understanding concerning the challenges faced by Sudanese refugees who predominantly settle in groups in major Australian cities and struggle with societal integration and finding permanent employment.

While the paper focuses on humanitarian entrants, usually classified as lacking the fundamental requirement (i.e., English proficiency) for integration into the wider community and for finding long- 
term gainful employment, it engages a framework of social entrepreneurship while undertaking forprofit activities and provides insights about challenges and potential business opportunities for Sudanese women refugees. Through the labour statistics and Australian government social support programs, and the interviews to members of SAIL (The Sudanese Australian Integrated Learning Program), the authors lay the fundaments on why their results may be different based on contextual issues. These range from logistical issues to attend programs; level of employment; community engagement; long-term job opportunities and unique cultural experience, that need to be considered with respect to the limitations that are framed by the social initiatives identified in relation to reducing unemployment for Sudanese women. In particular, programs that make use of existing skills (e.g., farming, cooking), create new opportunities in the employment market. In contrast, programs that provide new skills (e.g., English training), or a combination of new and existing skills, are more inclined to link to existing opportunities in the employment market. This paper provides understanding on these needs and constraints, thus suggesting valuable insights for the development of a business opportunity in support of communities from Africa, and women in particular.

The seventh paper, 'The influence of HR practices and job satisfaction on interpersonal deviance in the workplace' combines two separate streams of studies on the favourable relationship between HR practices and job satisfaction, and the effects of job satisfaction on work outcomes. The authors add to extant literature a nuanced understanding of the impact of HR practices (e.g., staffing, training and development, performance appraisal, and compensation and benefit management) on employees deviant behaviours (e.g., aggressive behaviour, bullying, harassment and incivility at work). Within the frameworks of social exchange theory and the norm of reciprocity, the authors empirically demonstrated on a sample from Malaysia that well-implemented HR practices can induce a positive emotional experience (i.e., job satisfaction) associated with tangible rewards and interpersonal relationships among employees, who in turn will be less likely to manifest such feeling in negative behaviour (i.e., deviant behaviour). This novel theoretical contribution emerging form an Asian-specific context now needs to be further strengthen by testing it's generalisability to Western Europe and North America contexts.

The seven papers in this edition provide a broad range of studies in management, which offer an overall view of management, as an area where research and investigation can examine issues at an international level and do so coherently by being context specific. It is a view that reveals the interconnectedness of management as a discipline. It is also where the human element continues to provide surprises and insights which may be individually unique - but which provide lessons that are relevant to organisations and practitioners by presenting tips for application and enhancing understanding. An important contribution of each of the papers chosen for this issue of JMO is that the research they present speaks to and engages a wider community. The broad range of topics contains issues that may be confronting to some and hopefully interesting to most but the real aim is to see management research as something that challenges and impact on users and that this is carried through into day-to-day management discussion and ultimately, into practice.

Tui McKeown, Laura Petitta

Monash University, Melbourne, Australia \& Sapienza University of Rome, Italy

\section{References}

ABC News (2010). Barbara Pocock comments on work-life balance for the ABC. August 5. Retrieved from http:// cpd.org.au/2010/08/work-life-bala/.

Aotahi Ltd (2008). Taking care of business: A guide to entrepreneurship in Aotearoa (2nd ed.). Te Kuiti, New Zealand: Aotahi Ltd.

Campbell, I. (2007). Long working hours in Australia: Working time regulation and employer pressures. The Economic and Labour Relations Review, 17(2), 37-68. 


\section{Editorial}

Corley, K. G., \& Gioia, D. A. (2011). Building theory about theory building: What constitutes a theoretical contribution? Academy Of Management Review, 36(1), 12-32.

DiTomaso, N., Post, C., \& Parks-Yancy, P. (2007). Workforce diversity and inequality: Power, status, and numbers. Annual Review of Sociology, 33, 473-501.

Farh, J. L., Hackett, R. D., \& Liang, J. (2007). Individual-level cultural values as moderators of the perceived organizational support-employee outcome relationships in China: Comparing the effects of power distance and traditionality. Academy of Management Journal, 50, 715-729.

Galvin, P. (2014). A new vision for the Journal of Management \& Organization: The role of context. Journal of Management \& Organization, 20(1), 1-5.

Geare, A., Cambell-Hunt, C., Ruwhiu, D., \& Bull, R. (2005). The New Zealand management supplement. North Ryde, NSW. Australia: McGraw-Hill.

Jack, G., \& Westwood, R. (2009). International and cross-cultural management studies. Hampshire, UK: Palgrave Macmillan.

Jones, G. (2011). Management: The Aotearoa New Zealand context (3rd ed.). Milton, Qld, Australia: John Wiley \& Sons.

Lambert, S. J. (2009). Lessons from the policy world: How the economy, work supports and education matter for low income workers. Work and Occupations, 36, 56-65.

Lambert, S. J., \& Haley-Lock, A. (2004). The organizational stratification of opportunities for work-life balance: Addressing issues of equality and social justice in the workplace. Community, Work \& Family, 7(2), 179-195.

Liden, R. C., \& Graen, G. (1980). Generalizability of the vertical dyad linkage model of leadership. Academy of Management Journal, 23(3), 451-465.

Özbilgin, M. F., Beauregard, T. A., Tatli, A., \& Bell, M. P. (2011). Work-life, diversity and intersectionality: A critical review and research agenda. International Journal of Management Reviews, 13(2), 177-198.

Pettigrew, A. M. (2011). Scholarship with impact. British Journal of Management, 22, 347-354.

Pocock, B. (2008). Work-life balance in Australia? Presentation to the International Workshop: Work-Life Balance in Japan, Australia and Canada, Institute for Gender Studies, Ochanomizu University, Tokyo, 16 March.

Ralston, D. A., Egri, C. P., Steward, S., Terpstra, R. H., \& Kaicheng, Y. (1999). Doing business in the 21 st century with the new generation of Chinese managers: A study of generational shifts in work values in China. Journal of International Business Studies, 30, 415-427.

Smith, L. T. (1999). Decolonizing methodologies: Research and indigenous peoples. London, UK and Dunedin, New Zealand: Zed Books and Otago University Press.

Tsui, A. S. (2004). Contributing to global management knowledge: A case for high quality indigenous research. Asia Pacific Journal of Management, 21, 491-513. 